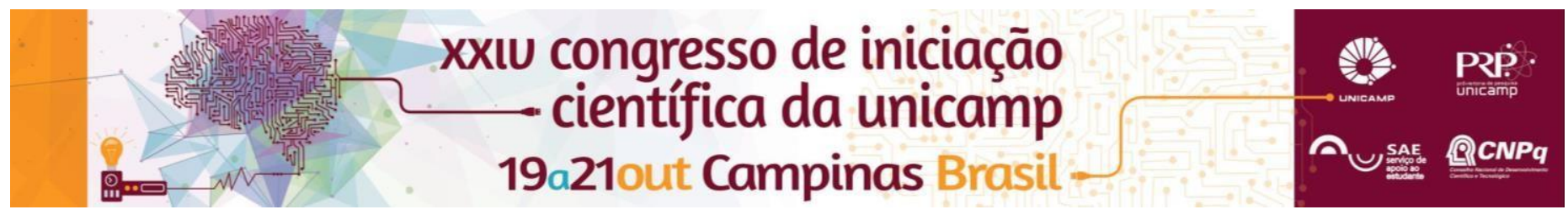

\title{
A THERMODYNAMIC ANALYSIS OF DIFFERENT CONFIGURATIONS FOR COGENERATION USING RANKINE CYCLES IN BIOREFINERIES
}

\author{
Jean W. P. Claudino*, Luiz F. Pellegrini, Carlos E. K. Mady
}

\begin{abstract}
Exergy analysis was applied to differents cogeneration Rankine cycles using biomass as fuel, aiming at evaluating the effect of increasing power production (electricity) and its maximization for the same demand of process steam. Moreover, it was studied the effect of different plant configurations units to meet certain need for process steam. To this aim, it will be proposed some modifications in the cycle in comparison with the standar configuration. Therefore, the use of reheating, preheating, condensing turbine, among others hybrid variation, are noteworthy for this type of analysis.
\end{abstract}

Key words: Biorefineries, Cogenerations using Rankine cycles, Exergy anaysis

\section{Introduction}

Exergy analysis was applied to evaluate different cogeneration systems in order to improve the efficiency of Rankine Cycles. Hence, for the same fuel intake, it is possible to obtain more products (process steam and electricity) which result in an improvement of natural resources consumption, decrease the emissions of pollutants and ensures the unit a greater reliability in the supply of certain energy demand (power or steam). Therefore, to improve the electricity generation and attempting to the process steam temperature and pressure necessity $(2.5,8$ and 15 bar), a configuration that resulted in the best efficiency was compared from the Second Law of Thermodynamics perspective with a standard Rankine cogeneration cycle. These analyzes were based in the discussions proposed by ${ }^{1}$. The mathematical model based on the First and Second Laws of Thermodynamics was proposed and simulations were carried out using the numerical solver $E E S \AA^{2}$. It was solved a different set of nonlinear equations: mass, energy, entropy and exergy balance of each equipment. Simulations were carried out using different process steam to fulfill a certain necessity of biorefinery (close to the saturation point) with pressure 2.5, 8 and 15 bar. These models were applied in nine configurations and compared with the one indicated in Image 1. It was adopted for the turbines and pumps an isentropic efficiency of $85 \%$. For the boiler, an efficiency of $80 \%$ was chosen. State 1 was fixed as 68 bar and $480^{\circ} \mathrm{C}$.

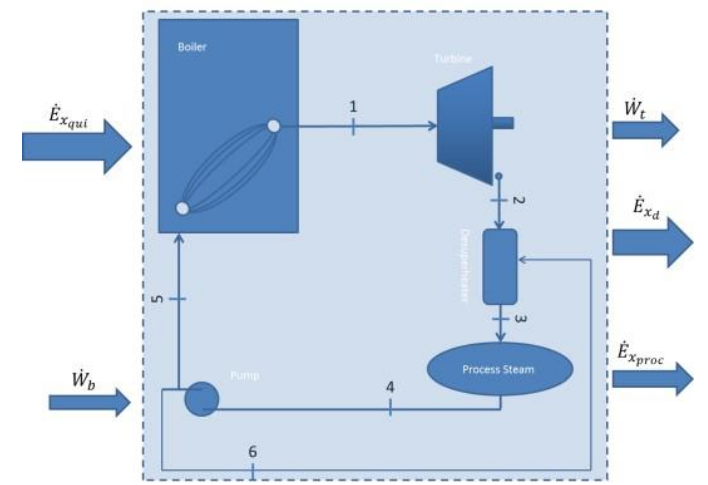

Image 1. Standard configuration of the standard Rankine Cycle and exergy inflows and outflow

Based on Image 1, it is possible to calculate the exergy efficiency according to Eq. (1)

$$
n_{e x}=\frac{W_{c y c}+\Delta E_{x, p r o c}}{E_{x, c h}}
$$

Where, $W_{c y}$ is the power output, $\Delta \mathrm{E}_{\mathrm{x}, \text { proc }}$ is the exergy variation of the process steam and $E_{x, c h}$ is the chemical exerqy of dry biomass ${ }^{1}$.

\section{Results and Discussion}

Different configurations were analyzed and the cycle indicated in the Image 2 was the one that obtained better results for exergy efficiency, with a maximum of $50 \%$ for a 15 bar process demand.

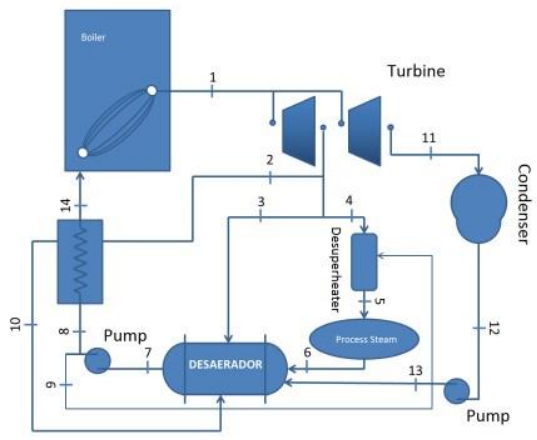

Image 2. Cogeneration Cycle using preheating and condensing turbine (extraction rate of $70 \%$ ).

In light of the obtained results, it can be stated that the relatively low influence of the reheating on the efficiency while, in contrast, there is a high influence of the preheating on the increase of the exergy efficiency, especially if it is associated with condensing turbines.

\section{Conclusions}

Based on the Thermodynamic model of the Rankine cogeneration cycle it was possible to obtain a cycle with an improvement of efficiency and power production, increasing the possibility of the biorefinery to profit with the power generation for the same process steam.

\section{Acknowledgement}

The authors would like to thanks the CNPq for the financial support that was given for the research.

${ }^{1}$ PELLEGRINI, L.F. Análise e Otimização Te rmo-econômica ambiental de Configurações de Plantas de Utilidades de Usinas de Açúcar, Álcool e Eletricidade. T ese (Dout orado em Engenharia Mecânica) - Escola Politécnica da Universidade de São Paulo, São Paulo, SP, 2009.

${ }^{2}$ KLEIN, S. A. Engineering Equation Solver (EES). F-Chart Software, 2008. 